BMJ Open

Sport \&

Exercise

Medicine

\title{
Chair-based fidgeting and energy expenditure
}

\author{
Gabriel A Koepp, ${ }^{1}$ Graham K Moore, ${ }^{1}$ James A Levine ${ }^{1,2}$
}

To cite: Koepp GA, Moore GK, Levine JA. Chair-based fidgeting and energy expenditure. BMJ Open Sport Exerc Med 2016;2:e000152.

doi:10.1136/bmjsem-2016000152

- Prepublication history for this paper is available online. To view these files please visit the journal online (http://dx.doi.org/10.1136/ bmjsem-2016-000152).

Accepted 14 August 2016

\section{CrossMark}

\footnotetext{
${ }^{1}$ Obesity Solutions, Mayo Clinic, Scottsdale, Arizona, USA

${ }^{2}$ Obesity Solutions, Arizona State University, Tempe, Arizona, USA

Correspondence to James A Levine;

Levine.james@mayo.edu
}

\begin{abstract}
Introduction: Sedentariness is associated with chronic health conditions, impaired cognitive function and obesity. Work contributes significantly to sedentariness because many work tasks necessitate sitting. Few sustained solutions exist to reverse workplace sedentariness. Here, we evaluated a chair and an under-table device that were designed to promote fidgeting while seated. Our hypothesis was that an under-table leg-fidget bar and/or a fidgetpromoting chair significantly increased energy expenditure. We compared these devices with chairbased exercise and walking.
\end{abstract}

Materials and methods: We measured energy expenditure and heart rate in 16 people while they sat and worked using a standard chair, an under-desk device that encourages leg fidgeting and a fidgetpromoting chair. We compared outcomes with chairbased exercise and walking.

Results: Energy expenditure increased significantly while using either an under-table leg-fidget bar or a fidget-promoting chair, when compared to the standard office chair (standard chair, $76 \pm 31 \mathrm{kcal} /$ hour; leg-fidget bar, $98 \pm 42 \mathrm{kcal} /$ hour $(p<0.001)$; fidget chair, $89 \pm 40 \mathrm{kcal} / \mathrm{hour}(\mathrm{p}=0.03))$. However, heart rate did not increase significantly in either case. Bouts of exercise performed while seated provided energetic and heart rate equivalency to walking at $2 \mathrm{mph}$.

Conclusions: Chairs and devices that promote fidgeting can increase energy expenditure by $\sim 20$ $30 \%$ but not increase heart rate. Dynamic sitting may be among a lexicon of options to help people move more while at work.

\section{INTRODUCTION}

Sedentariness is associated with a myriad of chronic diseases, impaired cognition ${ }^{1}$ and obesity. $^{2-5}$ The mechanism by which sitting excessively causes disease is not well understood, but it is known that breaking up sitting improves insulin sensitivity and lipids. ${ }^{6}$ Several studies have examined the effectiveness of programmes to displace sitting with standing or walking while working. ${ }^{7}{ }^{8}$ These measures can effectively decrease sitting time and improve productivity ${ }^{6910}$ although their
New findings

It is clear that chair-based fidgeting can increase energy expenditure.

How might it impact on clinical practice in the near future

- Chair-based fidgeting may be part of corporate weight maintenance or weight loss programmes.

- Chair-based fidgeting may be recommended by the medical community to reduce sedentary time at work.

long-term health benefits have not been proven.

When a person walks at even $1 \mathrm{mph}$, energy expenditure doubles when compared to basal metabolic rate. ${ }^{11} 12$ Sitting, however even while fidgeting, is not substantially exothermic (5-10\% increase above basal metabolic rate).$^{13-15}$ We wanted to assess whether chairs that promote 'dynamic sitting, ${ }^{16} 17$ can increase energy expenditure significantly above resting values. To this end, we examined the thermogenic impact of a chair designed specifically to encourage body fidgeting and an under-desk device that encourages leg fidgeting. In both cases, we measured the changes in energy expenditure and heart rate that accompanied their use. In order to better understand how we can encourage movement in people who need to work seated, we also examined the thermogenic and heart rate responses to chair-based exercises delivered through video. We compared these conditions to a $2 \mathrm{mph}$ walk since walking is known to improve health. ${ }^{18}$ Our hypothesis was that chairs and gadgets designed to promote fidgeting while seated are associated with an increase in energy expenditure. The null hypothesis was that chair-promoted fidgeting does not increase energy expenditure above resting values. Secondary hypotheses examined how 'dynamic sitting' influenced heart rate. 


\section{PARTICIPANTS AND METHODS}

\section{Participants}

Participants provided informed written consent, and the Mayo Clinic Institutional Review Board approved the protocol. Sixteen participants (nine women and seven men) were included with a mean $( \pm \mathrm{SD})$ age, $23 \pm 5$ years and body mass index (BMI), $26 \pm 5.5 \mathrm{~kg} / \mathrm{m}^{2}$ (table 1).

\section{Description of chairs}

Standard office chair (control chair): The criterion model chair is a standard office chair (Steelcase; Grand Rapids, Michigan, USA).

FootFidget, http://footfidget.com (FootFidget, Lake Zurich, Illinois, USA) (figure 1), is an under-desk elasticated footrest that encourages leg activity while seated. It comprises of a steel $17^{\prime \prime} \times 10^{\prime \prime} \times 10^{\prime \prime}$ frame support base. The elasticised central footpad consists of a 7 " foamcovered cylindrical rigid tube centred on two $17^{\prime \prime}$ flexible resistance cords that run through the tube and attach to the four upright legs on the stand. The user repeatedly 'bounces' their foot on the cylindrical tube that encounters resistance.

CoreChair, https://www.corechair.com (CoreChair, Aurora, Ontario, Canada) (figure 1), is a chair designed to promote activity while a person stays seated. It is a modified five-wheel office chair. It has a low, 9" backrest with adjustable depth and is without armrests. The seat is sculpted and covered in 2" thick foam padding. The main feature of the CoreChair is the mechanical core that allows for lateral movement while seated. Severity of seat tilt is adjustable and has a range of motion up to $14^{\circ}$ in all directions. For the study trial, tilt severity was set to allow for the greatest range of motion. Interchangeable centre columns of different lengths (tall and short) make the chair height-adjustable.

\section{Protocol}

Participants were tested in thermal comfort, 2 hours after eating and after $30 \mathrm{~min}$ of rest. Prior to testing, patients were shown the equipment and the experimental protocol was explained. Participants were weighed using a calibrated Seca 769 scale in light clothing (athletic shorts and t-shirt), and height was measured using a Seca 219 stadiometer without shoes (Seca, Chino, California, USA).

Participants were asked to sit on a standard office chair (Steelcase Criterion) for 20 min while working, checking email or using the internet. During this time, energy expenditure and heart rate were monitored.
Participants then continued their work-like activities and were provided with the FootFidget. Energy expenditure and heart rate were measured for $20 \mathrm{~min}$. Participants then sat on the CoreChair during which time energy expenditure and heart rate were measured for $20 \mathrm{~min}$. Participants remained sitting in the CoreChair, stopped their work-like activities and followed a $7 \mathrm{~min}$ chairbased exercise video. The participant was given a $5 \mathrm{~min}$ break. Subsequently, the participant followed the $7 \mathrm{~min}$ video for a second sample. Finally, participants walked at $2 \mathrm{mph}$ for $20 \mathrm{~min}$ on a calibrated treadmill (PaceMaster Bronze; Aerobics, West Caldwell, New Jersey, USA).

\section{Methods}

Energy expenditure

Energy expenditure was measured using indirect calorimetry $^{14}$ (Metamax 3B; Cortex, Leipzig, Germany). The calorimeter was calibrated using $5.0 \% \mathrm{CO}_{2}, 15.0 \% \mathrm{O}_{2}$, balance nitrogen (Praxair, Danbury, Connecticut, USA) and ambient air according to the manufacturer's specifications. In addition, it was volume calibrated before each participant using a $3 \mathrm{~L}$ syringe. The calorimeter collects breath-by-breath $\mathrm{CO}_{2}$ and $\mathrm{O}_{2}$ production and consumption, respectively, and energy expenditure is calculated using standard formulae. ${ }^{19}$

\section{Heart rate monitoring}

Participants were also fitted with a Polar Heart Rate Monitor H7 (Polar, Lake Success, New York, USA). Heart rate samples were recorded and synchronised for each breath.

\section{RESULTS}

Energy expenditure of the four seated conditions and slow walking $(2 \mathrm{mph})$ are shown in figure 2 . While sitting in the standard office chair, as expected, resting energy expenditure (sitting in a standard chair) showed a positive correlation with body weight $(\mathrm{r}=0.55, \mathrm{p}=0.03)$. The relationship was described by the equation; resting energy expenditure $\quad(\mathrm{kcal} /$ hour $)=0.976 \times$ weight $\quad(\mathrm{kg})$ \pm 0.917 .

Energy expenditure increased significantly while using the FootFidget $(\sim 30 \%)$ when compared to the standard office chair. Energy expenditure increased in all participants from a mean of $76 \pm 31$ to $98 \pm 42 \mathrm{kcal} /$ hour $(p<0.001)$. Heart rate did not increase significantly, however $(75 \pm 10$, cf $78 \pm 14 \mathrm{bpm})$. Similarly, energy expenditure increased significantly while using the

Table 1 Demographic information for 16 volunteers engaged in the study

\begin{tabular}{|c|c|c|c|c|c|}
\hline & Age (years) & Height (cm) & Weight (kg) & $\begin{array}{l}\text { Systolic blood } \\
\text { pressure (mm hg) }\end{array}$ & $\begin{array}{l}\text { Diastolic blood } \\
\text { pressure }(\mathrm{mm} \mathrm{hg})\end{array}$ \\
\hline $\begin{array}{l}9 \text { women; } \\
7 \text { men }\end{array}$ & $23 \pm 4.7$ & $170 \pm 10$ & $77 \pm 17$ & $116 \pm 18$ & $78 \pm 19$ \\
\hline
\end{tabular}


Figure 1 (A) FootFidget, http:// footfidget.com, and (B)

CoreChair, https://www.corechair. com.
A

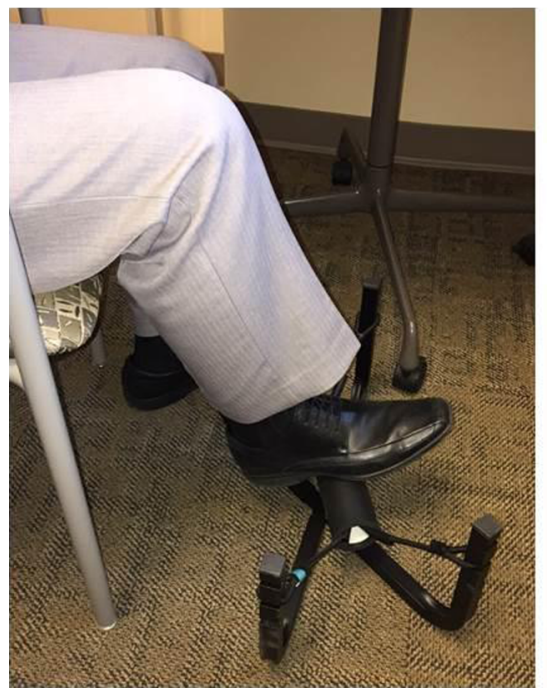

B

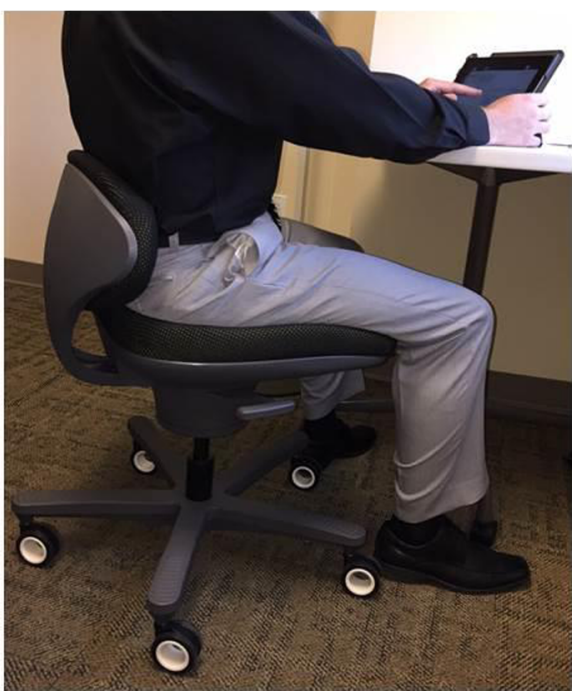

Energy expenditure (kcal/hour) $\square$ Heart Rate (Beats/min)

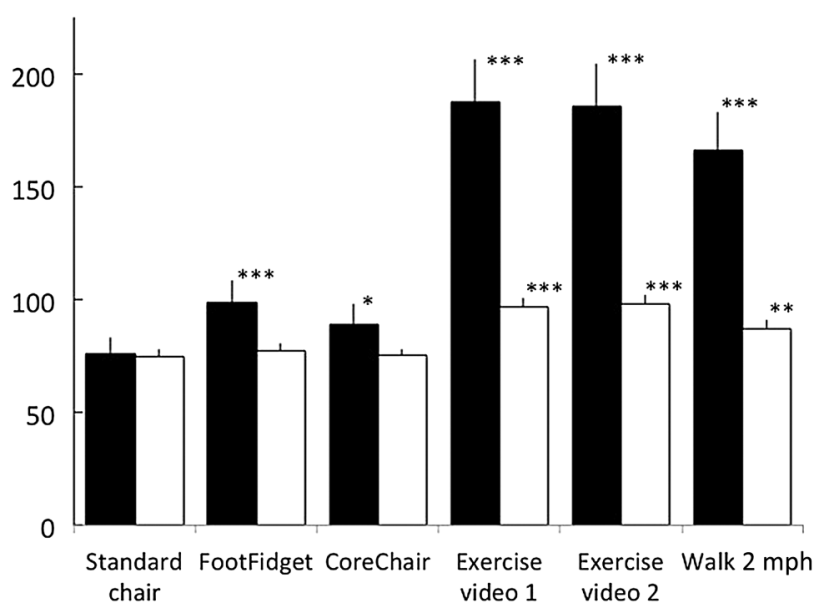

Figure 2 Energy expenditure and heart rate for 16 participants while (1) sitting in a standard office chair, (2) sitting in a standard chair using the FootFidget device, (3) sitting in the CoreChair while working, $(4,5)$ sitting in the CoreChair while completing one of two exercise videos and (6) walking on a treadmill at $2 \mathrm{mph}$. Data are shown as mean + SEM. ${ }^{\star} \mathrm{p}=0.03,{ }^{\star \star} \mathrm{p}=0.004,{ }^{\star \star \star} \mathrm{p}<0.001$.

CoreChair $(\sim 20 \%)$ when compared to sitting in a standard office chair $(76 \pm 31$, cf $89 \pm 40 \mathrm{kcal} /$ hour, $\mathrm{p}=0.03)$ and again heart rate did not significantly change $(75 \pm 10$, cf $75 \pm 11 \mathrm{bpm})$. When participants engaged in exercise videos while sitting in the CoreChair, energy expenditure more than doubled above sitting values $(76 \pm 31$, cf $189 \pm 77 \mathrm{kcal} /$ hour, $\mathrm{p}<0.001)$. Heart rate increased significantly as well, from $75 \pm 10$ to $97 \pm 11 \mathrm{bpm}(\mathrm{p}<0.001)$. These changes were physiologically similar to the changes in energy expenditure and heart rate that accompanied a $2 \mathrm{mph}$ walk (figure 1) $(166 \pm 64 \mathrm{kcal} /$ hour and $87 \pm 14 \mathrm{bpm})$.
Overall, footrests and chairs that encourage movement while working increase energy expenditure by about $20 \%$ but are not associated with increased heart rate. Interestingly, a person can participate in exercise while siting and increase energy expenditure and heart rate to levels comparable with taking a walk.

\section{DISCUSSION}

The importance of sedentariness in chronic disease and obesity is established. ${ }^{2} 7{ }^{20-23}$ Sedentary behaviours occur during work and while at home. ${ }^{24}$ Many people spend the majority of their weekly waking hours at work and so solutions to reverse sedentariness and promote physical activity are necessary. ${ }^{25}$

In adults, most sitting occurs while people are at work. ${ }^{26} 27$ This is attributed to the computer-based nature of modern work and to standard office design, both of which encourage employees to remain seated throughout the majority of work hours. Although standing and/or walking while working are attractive solutions for reversing excessive sitting, ${ }^{28}$ they are not practical for many employees. ${ }^{29}$ Another attractive example is to incorporate walking breaks throughout the workday; ${ }^{29} 30$ however, many companies cannot allow this because it interferes with workflow. ${ }^{31}$ Innovative approaches are needed to help sedentary office workers move more.

What can be performed to help employees who cannot get up from their desks? One approach could be to render sitting more active, which is called, 'dynamic sitting'. People who fidget while sitting can increase energy expenditure by $5-10 \%$ above resting values. ${ }^{14}$ In order to exploit this effect, several manufacturers have designed specific pieces of furniture that directly encourage an office worker to incorporate fidgeting movements while working at their usual business tasks. One popular example is replacing office chairs with large rubber balls (Swiss Balls). ${ }^{32}$ Using a Swiss Ball, an 
employee needs to continuously adjust their balance and deploy trunk and back muscles for support. Other 'dynamic sitting, ${ }^{33-35}$ solutions are being examined whereby furniture design is used to encourage chairbased fidgeting and/or leg movements. In this paper, we critically evaluated the thermogenic impact of these innovations.

The findings from our studies were clear. When a person sat on a chair that promoted fidgeting or used a footrest that promoted fidgeting, energy expenditure increased significantly by about $20 \%$. This degree of activity however was insufficient to increase heart rate. These studies also demonstrate that when a person partook of purposeful exercise while seated, energy expenditure increased twofold (figure 1). In this case, heart rate increased substantially as well-to the same degree as a $2 \mathrm{mph}$ walk. We concluded that chairs and gadgets that promote fidgeting while sitting at work are exothermic but are unlikely to contribute to aerobic fitness. However, a person can conduct an exercise routine while sitting in their office chair, which is exothermic and aerobic benefit.

There are few studies to directly compare these with. However, it is known that office furniture can be manipulated in order to promote daily activity whether this is through standing desks or treadmill desks. ${ }^{36}{ }^{37}$ These systems have been widely deployed in many companies, and direct, albeit limited, data show improved healthcare outcomes and benefit productivity. ${ }^{38} \quad 39$ Chair-based movement will need to go through a rigorous validation process in order to understand whether such devices benefit productivity and improve health.

There are several limitations to our studies, which we recognise. First, our studies were conducted in a laboratory environment, although we ensured that people partook of usual work tasks while measurements were gathered. Whether these approaches would sustain the responses we documented in the 'real world' will require a field-based study. Second, we did not directly assess true productive, which our prior work has shown to be critically important for successfully deploying these types of equipment in the workplace. ${ }^{36} 37$ Third, the changes in energy expenditure and heart rate we measured are sufficiently encouraging that we would want to conduct future studies to assess health impact (eg, glucose and lipids). However, the data shown above are only suggestive of such benefits. Despite these limitations, the results of these straightforward experiments are encouraging. They suggest that it may be worthwhile examining 'dynamic sitting' interventions in real-world workplaces.

In conclusion, here we demonstrate that chair design and under-desk gadgets can improve energy expenditure. Furthermore, the data demonstrate that the chair-based exercise can significantly increase energy expenditure and heart rate to the same extent as a $2 \mathrm{mph}$ walk. The value of such approaches in real-world offices remains to be determined. Innovative approaches are necessary to help reverse sedentary behaviour and the ill health associated with it.

Acknowledgements The authors thank volunteers and Sabrina J Nelson for technical support.

Competing interests None declared

Patient consent Obtained.

Ethics approval Mayo Clinic.

Provenance and peer review Not commissioned; externally peer reviewed.

Data sharing statement No additional data are available.

Open Access This is an Open Access article distributed in accordance with the Creative Commons Attribution Non Commercial (CC BY-NC 4.0) license, which permits others to distribute, remix, adapt, build upon this work noncommercially, and license their derivative works on different terms, provided the original work is properly cited and the use is non-commercial. See: http:// creativecommons.org/licenses/by-nc/4.0/

\section{REFERENCES}

1. Falck RS, Davis JC, Liu-Ambrose T. What is the association between sedentary behaviour and cognitive function? A systematic review. Br J Sports Med 2016; nn.

2. Saunders TJ, Chaput JP, Tremblay MS. Sedentary behaviour as an emerging risk factor for cardiometabolic diseases in children and youth. Can J Diabetes 2014;38:53-61.

3. Dunstan DW, Thorp AA, Healy GN. Prolonged sitting: is it a distinct coronary heart disease risk factor? Curr Opin Cardiol 2011;5:412-19.

4. Hamilton MT, Hamilton DG, Zderic TW. Role of low energy expenditure and sitting in obesity, metabolic syndrome, type 2 diabetes, and cardiovascular disease. Diabetes 2007;56:2655-67.

5. van der Ploeg HP, Chey T, Korda RJ, et al. Sitting time and all-cause mortality risk in 222497 Australian adults. Arch Intern Med 2012;172:494-500.

6. Dunstan DW, Kingwell BA, Larsen R, et al. Breaking up prolonged sitting reduces postprandial glucose and insulin responses. Diabetes Care 2012;35:976-83.

7. Prince SA, Saunders TJ, Gresty K, et al. A comparison of the effectiveness of physical activity and sedentary behaviour interventions in reducing sedentary time in adults: a systematic review and meta-analysis of controlled trials. Obes Rev 2014;15:905-19.

8. Pronk NP, Katz AS, Lowry M, et al. Reducing occupational sitting time and improving worker health: the Take-a-Stand Project, 2011. Prev Chronic Dis 2012;9:E154.

9. Hamilton MT, Healy GN, Dunstan DW, et al. Too little exercise and too much sitting: inactivity physiology and the need for new recommendations on sedentary behavior. Curr Cardiovasc Risk Rep 2008;2:292-8

10. Thorp AA, Owen N, Neuhaus M, et al. Sedentary behaviors and subsequent health outcomes in adults a systematic review of longitudinal studies, 1996-2011. Am J Prev Med 2011;41:207-15.

11. Bouten CV, Westerterp KR, Verduin M, et al. Assessment of energy expenditure for physical activity using a triaxial accelerometer. Med Sci Sports Exerc 1994;26:1516-23.

12. Foster GD, Wadden TA, Kendrick ZV, et al. The energy cost of walking before and after significant weight loss. Med Sci Sports Exerc 1995;27:888-94

13. Dietz WH, Bandini LG, Morelli JA, et al. Effect of sedentary activities on resting metabolic rate. Am J Clin Nutr 1994;59:556-9.

14. Levine JA, Schleusner SJ, Jensen MD. Energy expenditure of nonexercise activity. Am J Clin Nutr 2000;72:1451-4.

15. Ravussin E, Lillioja S, Anderson TE, et al. Determinants of 24-hour energy expenditure in man. Methods and results using a respiratory chamber. J Clin Invest 1986;78:1568-78.

16. Mörl F, Bradl I. Lumbar posture and muscular activity while sitting during office work. J Electromyogr Kinesiol 2013;23:362-8.

17. O'Sullivan K, O'Keeffe M, O'Sullivan L, et al. The effect of dynamic sitting on the prevention and management of low back pain and low back discomfort: a systematic review. Ergonomics 2012;55:898-908.

18. Buckley JP, Hedge A, Yates T, et al. The sedentary office: an expert statement on the growing case for change towards better health and productivity. 2015;49:1357-62. 
19. Weir JB. New methods for calculating metabolic rate with special reference to protein metabolism. Nutrition 1949;6:213-21.

20. Hamilton MT, Hamilton DG, Zderic TW. Sedentary behavior as a mediator of type 2 diabetes. Med Sport Sci 2014;60:11-26.

21. Prince SA, Gresty KM, Reed JL, et al. Individual, social and physical environmental correlates of sedentary behaviours in adults: a systematic review protocol. Syst Rev 2014;3:120.

22. Cerimele JM, Katon WJ. Associations between health risk behaviors and symptoms of schizophrenia and bipolar disorder: a systematic review. Gen Hosp Psychiatry 2013;35:16-22.

23. Tudor-Locke C, Schuna JM, Jr. Steps to preventing type 2 diabetes: exercise, walk more, or sit less? Front Endocrinol (Lausanne) 2012;3:142

24. McCrady SK, Levine JA. Sedentariness at work: how much do we really sit? Obesity (Silver Spring) 2009;17:2103-5.

25. Levine JA. Health-chair reform: your chair: comfortable but deadly. Diabetes 2010;59:2715-16.

26. Ng SW, Popkin BM. Time use and physical activity: a shift away from movement across the globe. Obes Rev 2012;13:659-80.

27. Dunton GF, Berrigan D, Ballard-Barbash R, et al. Environmental influences on exercise intensity and duration in a US time use study. Med Sci Sports Exerc 2009;41:1698-705

28. Dempsey PC, Larsen RN, Sethi $\mathrm{P}$, et al. Benefits for type 2 diabetes of interrupting prolonged sitting with brief bouts of light walking or simple resistance activities. Diabetes Care 2016;39:964-72.

29. Júdice PB, Hamilton MT, Sardinha LB, et al. Randomized controlled pilot of an intervention to reduce and break-up overweight/obese adults' overall sitting-time. Trials 2015;16:490.

30. Levin C, Chisholm D. Cost-effectiveness and affordability of interventions, policies, and platforms for the prevention and treatment of mental, neurological, and substance use disorders. In: Patel V, Chisholm D, Dua T, Laxminarayan R, Medina-Mora $\mathrm{ME}$, eds. Mental, neurological, and substance use disorders: disease control priorities. 3rd edn. Vol 4. Washington (DC): The International Bank for Reconstruction and Development/The World Bank, 2016:219-36.

31. Stengård J, Bernhard-Oettel C, Berntson E, et al. Stuck in a job: being "locked-in" or at risk of becoming locked-in at the workplace and well-being over time. Work Stress 2016;30:152-72.

32. Marks CR, Dupuie L, Patros J. Stability ball sitting elevates peak arm ergometry oxygen consumption and heart rate. Int J Exerc Sci 2012;5:360-6.

33. Pynt J. Rethinking design parameters in the search for optimal dynamic seating. J Bodyw Mov Ther 2015;19:291-303.

34. Lamar DL, Chou SH, Medverd JR, et al. Sedentary behavior in the workplace: a potential occupational hazard for radiologists. Curr Probl Diagn Radiol 2016;45:253-7.

35. Chatchawan U, Jupamatangb U, Chanchitc S, et al. Immediate effects of dynamic sitting exercise on the lower back mobility of sedentary young adults. J Phys Ther Sci 2015;27:3359-63.

36. Ben-Ner A, Hamann DJ, Koepp G, et al. Treadmill workstations: the effects of walking while working on physical activity and work performance. PLoS One 2014;9:e88620.

37. Koepp GA, Manohar CU, McCrady-Spitzer SK, et al. Treadmill desks: a 1-year prospective trial. Obesity 2013;21:705-11.

38. John D, Bassett D, Thompson D, et al. Effect of using a treadmill workstation on performance of simulated office work tasks. J Phys Act Health 2009;6:617-24.

39. Thompson WG, Levine JA. Productivity of transcriptionists using a treadmill desk. Work 2011;40:473-7. 